\title{
Multimodality Imaging for Cardiac Evaluation in Patients with COVID-19
}

\author{
Erin Goerlich ${ }^{1}$ (I) $\cdot$ Anum S. Minhas ${ }^{1}$ (D) $\cdot$ Monica Mukherjee ${ }^{1}$ (D) $\cdot$ Farooq H. Sheikh $^{2}$ (D) - Nisha A. Gilotra ${ }^{1}$ (D) \\ Garima Sharma ${ }^{1}$ (D) Erin D. Michos ${ }^{1,3}$ (D) - Allison G. Hays ${ }^{1}$ (I)
}

Accepted: 17 February 2021 / Published online: 15 March 2021

(C) The Author(s), under exclusive licence to Springer Science+Business Media, LLC part of Springer Nature 2021

\begin{abstract}
Purpose of Review A growing number of cardiovascular manifestations resulting from the novel SARS-CoV-2 coronavirus (COVID-19) have been described since the beginning of this global pandemic. Acute myocardial injury is common in this population and is associated with higher rates of morbidity and mortality. The focus of this review centers on the recent applications of multimodality imaging in the diagnosis and management of COVID-19-related cardiovascular conditions.

Recent Findings In addition to standard cardiac imaging techniques such as transthoracic echocardiography, other modalities including computed tomography and cardiac magnetic resonance imaging have emerged as useful adjuncts in select patients with COVID-19 infection, particularly those with suspected ischemic and nonischemic myocardial injury. Data have also emerged suggesting lasting COVID-19 subclinical cardiac effects, which may have long-term prognostic implications.

Summary With the spectrum of COVID-19 cardiovascular manifestations observed thus far, it is important for clinicians to recognize the role, strengths, and limitations of multimodality imaging techniques in this patient population.
\end{abstract}

Keywords COVID-19 $\cdot$ Cardiovascular $\cdot$ Myocardial injury $\cdot$ Multimodality imaging

\section{Introduction}

Coronavirus disease 2019 (COVID-19), caused by infection with the severe acute respiratory syndrome coronavirus 2 (SARS-CoV-2), has resulted in high rates of worldwide morbidity and mortality. While the most common organ system affected remains the respiratory tract, a wide variety of important cardiac manifestations have been described [1,2]. Acute

This article is part of the Topical Collection on Cardiac PET, CT, and MRI

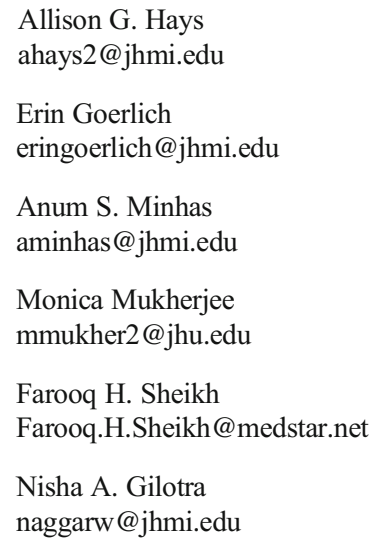

myocardial injury, defined by elevated troponin level above the 99th percentile upper reference limit, is relatively common in COVID-19 and is independently associated with adverse outcomes [3, 4]. Furthermore, patients with COVID-19 are at risk for cardiovascular (CV) events including cardiac arrhythmias, myocardial infarction, heart failure, and stroke [1]. With increasing recognition of CV complications of COVID-19, the role of cardiac imaging techniques used to diagnose,
Garima Sharma

gsharma8@jhmi.edu

Erin D. Michos

edonnell@jhmi.edu

1 Division of Cardiology, Department of Medicine, Johns Hopkins University School of Medicine, 600 N. Wolfe Street, Carnegie 568, Baltimore, MD 21287, USA

2 Division of Cardiology, Department of Medicine, Medstar Washington Hospital Center, Washington, DC, USA

3 Department of Epidemiology, Johns Hopkins Bloomberg School of Public Health, Baltimore, MD, USA 
manage, and monitor COVID-19 patients has evolved [5•, 6•]. More recent studies have focused on the detection of subclinical cardiac dysfunction and persistent cardiac inflammation and scar resulting from myocardial injury.

\section{Pathophysiology of COVID-19 Cardiovascular Effects}

The reported incidence of myocardial injury, as measured by troponin, has been widely variable, ranging from 7 to $51 \%$ in COVID-19 patient cohorts [7, 8•, 9]. The forms of COVID19-related CV injury generally fall into the following categories: primary damage resulting from direct viral effect; secondary damage as a consequence of other organ or systemic dysfunction; and importantly, exacerbation of baseline CV disease by either primary or secondary causes [10]. The reported CV complications have included clinical and subclinical myocardial dysfunction, heart failure, myocarditis, cardiac arrhythmias, myocardial infarction, stress cardiomyopathy, pericarditis, vasculitis, circulatory shock, pulmonary hypertension, and thromboembolism [2,11-13].

Although there is a wide range of documented effects on the CV system in COVID-19, the underlying cellular mechanisms are multifaceted and incompletely understood [12, 14-16]. SARS-CoV-2 gains entry into cells via binding of its viral spike protein to angiotensin-converting enzyme 2 (ACE2), which resides on a variety of cell surfaces throughout the body, including cardiomyocytes and vascular endothelial cells $[17,18]$. A common initial point of entry is the respiratory epithelial cell, which has high levels of ACE2 [19]. Subsequent viral invasion of other tissues expressing membrane-bound ACE2, such as the myocardium, can then occur with resultant cytotoxicity and organ dysfunction. Autopsy studies have demonstrated evidence of viremia with SARS-CoV-2 RNA and active replication particles in myocardial interstitial tissue [20,21]. Direct viral invasion of vascular endothelial cells with associated inflammation and damage to the vascular endothelial membrane has also been discovered on histological specimens [22].

A major consequence of SARS-CoV-2 viral replication and hematogenous spread is the downregulation of ACE2, resulting in numerous adverse downstream effects. Loss of ACE2 reduces degradation of angiotensin II, thus leading to cardiomyocyte hypertrophy, myocardial and endothelial dysfunction, vasoconstriction, and local inflammation [23, 24]. Similar processes additionally lead to platelet dysfunction and heightened thrombosis $[25,26]$. Furthermore, indirect cellular damage is hypothesized to occur by widespread immune activation and cytokine release [11, 25, 27-29]. Significant elevations in proinflammatory cytokines such as interleukin-6, C-reactive protein, tumor necrosis factor alpha, and ferritin in patients with COVID-19 are frequently reported
[30-32]. These circulating molecules may then release reactive oxygen species, acutely depress myocardial contractility, trigger cardiac arrhythmias, cause localized arterial inflammation, and lead to secondary CV damage via cardiomyopathy, acute coronary syndrome, and thrombosis [11, 25, 27]. Other secondary mechanisms of injury include electrolyte imbalance, hypoxia, medication effect, catecholamine surge, and overall increased cardiometabolic demand [25]. Given the breadth of potential cardiovascular effects of COVID-19, multimodality imaging can provide integral information to guide diagnosis and management.

\section{Cardiac Imaging Modalities in COVID-19}

\section{Echocardiography}

The most commonly utilized imaging modality for dedicated cardiac evaluation in COVID-19 is transthoracic echocardiography (TTE), which is safe, easily accessible, and portable. Although many have reported a high incidence of myocardial injury based on troponin elevation in COVID-19, Giustino et al. found that myocardial injury plus abnormal finding on TTE, but not myocardial injury alone, were associated with a higher risk of death, suggesting an added prognostic benefit to this imaging modality [33]. When compared to acute respiratory distress (ARDS) patients without COVID-19, those with COVID-19-related ARDS have similar troponin levels, which can be largely explained by underlying comorbidities and illness severity [8•]. This may suggest incremental value in cardiac imaging beyond a serum troponin level. The major benefits to TTE are the ability to be rapidly performed at the patient's bedside, relative ease of use, and lack of radiation (Table 1). The American Society of Echocardiography has issued statements to guide clinicians on use of TTE safely, efficiently, and appropriately amidst the COVID-19 pandemic $[34 \bullet \cdot, 35]$. One of the drawbacks of TTE, and the major reason use has been discouraged in COVID-19 patients who are lacking a specific cardiopulmonary question to be answered, is the viral transmission risk. TTE requires sonographers to make direct and prolonged patient contact [36]. Despite these risks, TTE is considered by major society guidelines to be a safe option when there is an appropriate clinical indication and when sanitization and PPE guidelines are followed [34••, 37].

Standard TTE ultrasound images can provide important information about cardiac structure and function. In an international prospective survey of 1216 COVID-19 patients undergoing TTE, the most common imaging indications were suspected heart failure in $40 \%$, cardiac biomarker elevation in $26 \%$, and right-sided heart failure in $20 \%$, which changed patient management in $33 \%$ of cases [38]. Both left and right ventricular functional assessments are essential in patients with suspected cardiomyopathy, myocarditis, myocardial infarction, 
Table 1 Characteristics of imaging modalities for COVID-19 patient care

\begin{tabular}{|c|c|c|c|}
\hline Imaging modality & Advantages & Disadvantages & COVID-19 findings \\
\hline \multirow[t]{2}{*}{ Echocardiography } & $\begin{array}{l}\text { - Rapid } \\
\text { - Performed bedside }\end{array}$ & - Sonographer infectious exposure & - RV dilation and dysfunction \\
\hline & $\begin{array}{l}\text { - No radiation } \\
\text { - Low cost }\end{array}$ & $\begin{array}{l}\text { - Image quality often compromised by } \\
\text { patient habitus or ventilation }\end{array}$ & $\begin{array}{l}\text { - LV systolic and diastolic dysfunction } \\
\text { - Wall motion abnormalities } \\
\text { - Stress cardiomyopathy } \\
\text { - Pulmonary hypertension } \\
\text { - Reduced LV and RV strain } \\
\text { - Pericardial effusion } \\
\text { - Elevated filling pressures }\end{array}$ \\
\hline \multirow[t]{4}{*}{ Point-of-care ultrasound } & - Rapid & - Infectious exposure to provider & $\begin{array}{l}\text { - Basic LV and RV structural and } \\
\text { functional abnormalities }\end{array}$ \\
\hline & • No radiation & & \\
\hline & $\begin{array}{l}\text { - Low cost } \\
\text { - Minimal equipment }\end{array}$ & $\begin{array}{l}\text { - Image quality compromised by patient } \\
\text { habitus or ventilation }\end{array}$ & $\begin{array}{l}\text { - Pericardial effusion } \\
\text { - Pleural effusion }\end{array}$ \\
\hline & & $\begin{array}{l}\text { - More limited functionality compared } \\
\text { to echocardiography }\end{array}$ & $\begin{array}{l}\text { - B lines (may indicate interstitial edema } \\
\text { on lung ultrasound) }\end{array}$ \\
\hline \multirow[t]{3}{*}{ СТ/CTPA/CTA } & • Rapid & - Radiation & - Pulmonary embolism \\
\hline & - High resolution & - Risks of iodine contrast & $\begin{array}{l}\text { - Cardiomegaly } \\
\text { - Chamber size }\end{array}$ \\
\hline & $\begin{array}{l}\text { - Moderate cost } \\
\text { - Some tissue characterization }\end{array}$ & - Not bedside & $\begin{array}{l}\text { - Intracardiac thrombus } \\
\text { - Pericardial effusion }\end{array}$ \\
\hline \multirow[t]{2}{*}{ CMR } & $\begin{array}{l}\text { - High resolution } \\
\text { - Functional imaging } \\
\text { - Superior tissue characterization }\end{array}$ & $\begin{array}{l}\text { - Expensive } \\
\text { - Time-consuming } \\
\text { - Frequent patient intolerance and } \\
\text { incompatibilities }\end{array}$ & $\begin{array}{l}\text { - Ischemic vs nonischemic injury } \\
\text { - Stress cardiomyopathy } \\
\text { - Myocarditis } \\
\text { - Pericarditis }\end{array}$ \\
\hline & - No radiation & & $\begin{array}{l}\text { - Chamber enlargement } \\
\text { - Strain abnormalities }\end{array}$ \\
\hline \multirow[t]{2}{*}{ Nuclear imaging } & - Inflammation localization & $\begin{array}{l}\text { - Low resolution } \\
\text { - Time-consuming }\end{array}$ & $\begin{array}{l}\text { - Valvular inflammation in endocarditis } \\
\text { (FDG-PET alternative to TEE) }\end{array}$ \\
\hline & & - Radiation exposure & - Myocardial inflammation in myocarditis \\
\hline
\end{tabular}

pulmonary hypertension, or pulmonary embolism. Abnormal left ventricular (LV) systolic function is primarily detected as reduced LV ejection fraction (LVEF) and/or focal LV wall motion abnormalities on TTE. A specific pattern of predominantly apical LV wall motion abnormality with or without apical ballooning can support a diagnosis of stress-induced, or Takotsubo, cardiomyopathy [39]. This condition can occur more often in patients with sepsis, shock, or hypoxia, and despite typically being a diagnosis of exclusion, has been described in several reports of COVID-19 patients [40, 41]. Due to frequent difficulties in adequate image acquisition in the critically ill COVID-19 patients, it is important to note that the use of ultrasonic enhancing agents (commonly known as echocardiographic contrast) can safely improve the diagnostic yield of bedside TTE [42]. The aforementioned international study by Dweck et al. reported LV abnormalities in 39\% of patients, and LVEF was $<50 \%$ in over $25 \%$ of patients in a similar cohort $[33,43]$. However, this moderate prevalence of LV systolic dysfunction is not consistent across all studies investigating echocardiography in COVID-19. Another study reported that among 100 COVID-19 patients who underwent TTE within $24 \mathrm{~h}$ of admission, the most common findings were right ventricular (RV) dilation and dysfunction in $39 \%$ and LV systolic dysfunction in only $10 \%$ [44].

$\mathrm{RV}$ function is commonly assessed by quantifying chamber size, tricuspid annular plane systolic excursion (TAPSE), and RV systolic velocity via tissue Doppler imaging [45]. Isolated RV dysfunction in the setting of COVID-19 infection may suggest acute pulmonary hypertension, right-sided myocardial infarction, or even focal myocarditis [46]. Given the high 
incidence of ARDS requiring mechanical ventilation and the hypercoagulable state of many patients with severe COVID19 , it is thought that damage to both the lung parenchyma and the pulmonary microvasculature contributes to RV dilation and dysfunction in this setting [47]. Cor pulmonale due to a sudden increase in RV afterload has also been reported [48]. In COVID19 , this most commonly results from pulmonary embolism or hypoxic respiratory failure with elevated airway pressures. Nonetheless, the finding of RV dysfunction or remodeling portends a poor overall prognosis in COVID-19 [46, 49, 50]. In addition, positive end-expiratory pressure, a common adjunctive support in COVID-19 lung disease, can acutely impair the RV, and such dysfunction that persists on repeat TTE has been shown to correlate with adverse outcomes [51].

LV diastolic dysfunction is most commonly assessed with pulse wave Doppler at the level of the mitral valve in combination with chamber sizes and may be the only TTE abnormality seen in patients with heart failure with preserved ejection fraction [52]. Diastolic dysfunction has been reported in COVID-19, though it can be difficult to determine the acuity of this finding in patients with high prevalence of underlying comorbidities such as hypertension and diabetes [44]. The mitral valve $\mathrm{E} / \mathrm{e}^{\prime}$ ratio can be used to noninvasively estimate left-sided cardiac filling pressure, and has been shown to be elevated frequently in patients with COVID-19 [52, 53].

As can also be seen on standard TTE, pericardial effusions have been noted in several COVID-19 case studies, along with the rare yet important diagnosis of pericardial tamponade secondary to COVID-19 pericarditis or perimyocarditis [54-58]. These effusions are likely related to active inflammation in the setting of systemic infection.

\section{Specialized Echocardiographic Techniques}

In the era of COVID-19, point-of-care ultrasound (POCUS) has emerged as an adjunct to standard TTE and has played an important role in the care of COVID-19 patients by allowing for more rapid patient assessment with lower equipment burden and viral transmission risk [59]. POCUS can generally be used to quickly assess the same transthoracic structures discussed above, albeit at slightly lower resolution and often without Doppler features $[60,61]$. Abnormal findings on POCUS have been utilized to identify patients who might benefit from complete TTE and thus limit unnecessary testing and exposures. It has also been used to monitor certain cardiac or pulmonary parameters over time when serial TTE, or clinical physical exam, were not easily obtained [60]. POCUS has been highly utilized for bedside lung ultrasound during the COVID-19 pandemic, showing strong ability to identify small pleural effusions and parenchymal consolidations and thus limiting the need for chest computed tomography (CT) in many cases [62].

Recent technological advances have expanded the diagnostic and prognostic capabilities of standard echocardiography.
Speckle tracking echocardiography (STE) is a newer noninvasive modality used in conjunction with conventional 2 dimensional-based TTE that calculates the percent change in myocardial deformation throughout the cardiac cycle to provide precise estimation of regional and global contractile function known as strain [63]. Although most commonly used for the LV, STE can be applied to any chamber utilizing an offline post-processing software and has proven useful in identifying subclinical myocardial dysfunction in COVID-19 [64]. Both LV and RV strain have been found to be significantly reduced and predictive of mortality in patients with COVID-19 (Fig. 1) $[50,64,65]$. A frequent pattern of basal LV strain reduction has also been reported, suggesting areas of enhanced myocardial susceptibility to COVID-19-related damage [66, 67]. One study determined that longitudinal assessment of RV function via TAPSE and RV free-wall strain actually underestimated the degree of radial impairment in COVID-19 and suggested that RV fractional area change (FAC) and RV-pulmonary artery coupling (calculated as FAC/RVSP) may be more useful measurements of RV function in COVID-19 [68].

A newer advance in echocardiography is myocardial work assessment, which uses STE-derived strain indexed to systolic blood pressure to provide a more load-independent measure of systolic function. It has not been extensively studied in COVID-19; however, reduced myocardial work efficiency has been associated with increased mortality, and one case report noted reduced myocardial work index as the only abnormal, and thus possibly an early, marker of myocardial dysfunction using TTE $[69,70]$.

\section{Transesophageal Echocardiography}

Due to heightened infectious risk from patient aerosol production, the use of transesophageal echocardiography (TEE) has declined since the outbreak of COVID-19 in favor of noninvasive imaging options, when available. The American Society of Echocardiography released guidelines specifically instructing providers to defer TEE whenever feasible in patients with COVID positivity [34••]. As a result, many institutions have transitioned from the utilization of TEE for some indications such as exclusion of left atrial appendage thrombus prior to cardioversion to gated cardiac CT when feasible [71].

\section{Computed Tomography}

The role of CT in COVID-19 patient care began early in the pandemic, as many patients undergo chest CT in the diagnostic workup for respiratory symptoms. Benefits to this modality include quick speed, high spatial resolution and tissue characterization, and noninvasive nature, while the cons consist of radiation exposure and the risks of administering intravenous contrast (Table 1) [72]. The discussion of CT utility in the COVID-19 literature to date mainly focuses on the evaluation 


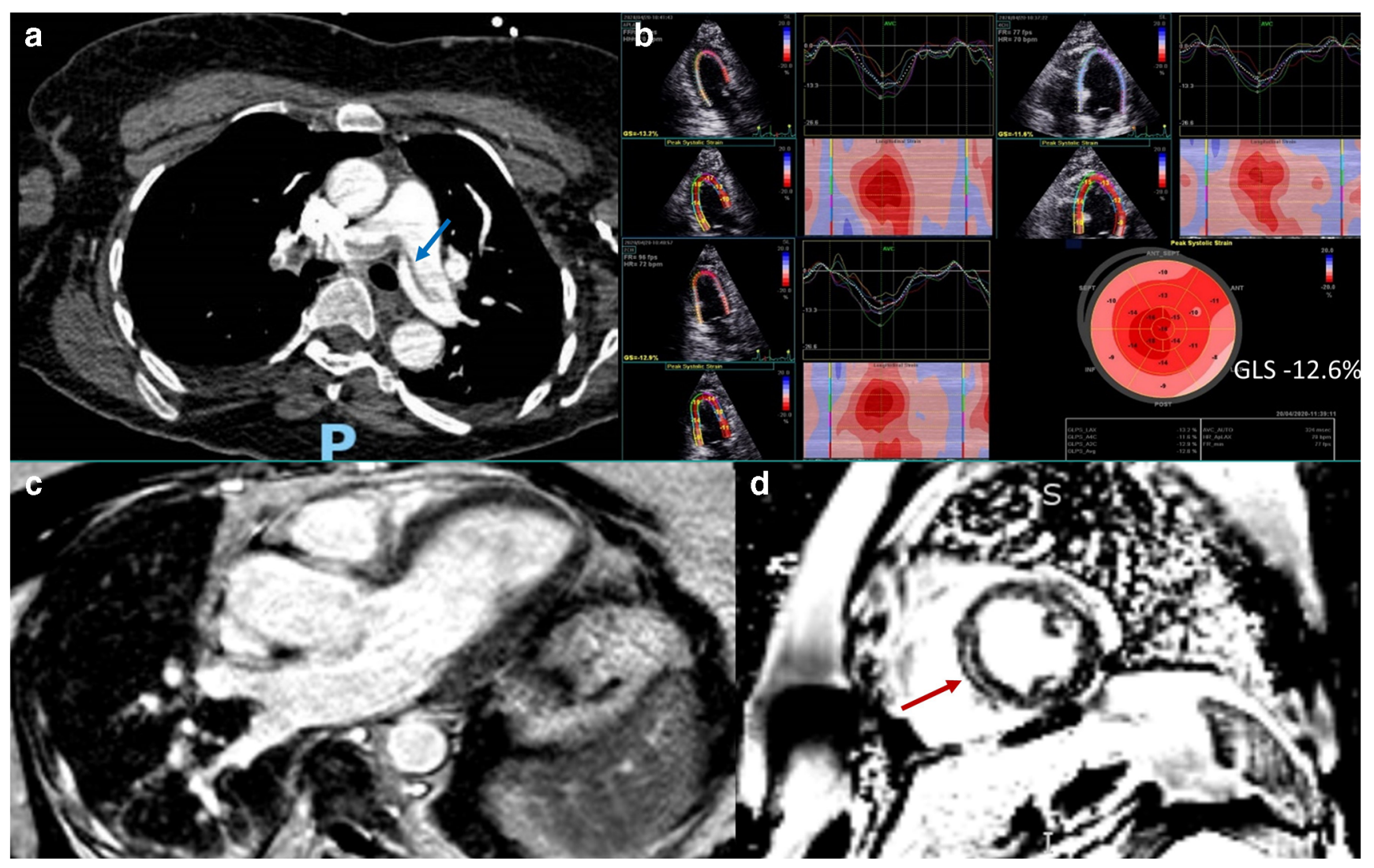

Fig. 1 Examples of imaging findings in COVID-19. (a) Computed tomography-pulmonary angiography (CTPA) displaying a saddle pulmonary embolism (blue arrow). (b) Transthoracic echocardiography images showing reduced global left ventricular (LV) strain at $-12.6 \%$.
Cardiac magnetic resonance scan showing (c) patchy late gadolinium enhancement of the LV consistent with scar/fibrosis with (d) prominent mid-myocardial enhancement (red arrow) seen in the short-axis view for pulmonary embolism, myocarditis, acute coronary syndrome, and exclusion of left atrial thrombi prior to cardioversion; however, there is value in the evaluation of other $\mathrm{CV}$ complications as well [72, 73].

When performed as a non-contrast, non-cardiac-gated scan, CT insights into cardiac structure and function are largely limited to morphology of heart chambers and great vessels and presence of pericardial effusion. In addition, CT enables the quantification of coronary calcifications which are not inherently related to COVID-19 infection, however, are common in patients with CV risk factors, and frequently present in hospitalized COVID-19 patients [74]. CT of the chest without contrast mainly ordered for evaluation of lung pathology in COVID-19 can also provide important CV information, especially in the setting of acute or chronic kidney injury precluding the use of intravenous contrast. For example, imaging features of heart failure such as the appearance of pulmonary veins can be detected with chest CT, and this modality has been shown to be helpful in differentiating COVID-19 pneumonia from acute decompensated heart failure when presenting signs and symptoms were similar and difficult to distinguish clinically [75].
When contrast is used with chest CT, however, as in the case of the CT-pulmonary angiography (CTPA) for pulmonary embolism evaluation, it provides more detailed information relevant to $\mathrm{CV}$ complications (Fig. 1). COVID-19 infection leads to a hypercoagulable state, and studies have cited high rates of pulmonary embolism incidence, ranging from 2.6 to $24 \%$ [76-78]. Accordingly, CTPA can also diagnose right atrial thrombus, which has been seen in COVID-19 patients [79]. In addition to diagnosing the presence and grading the severity of pulmonary emboli, CTPA allows for better visualization of cardiac chamber size, intraventricular septal bowing, and aortic pathology. Contrast-enhanced CT can be combined with cardiac gating to evaluate for myocardial edema, scarring, and fibrosis when cardiac magnetic resonance imaging (CMR) is unavailable. Cardiac CT in these cases can be useful in the evaluation of COVID-19 myocarditis via subepicardial delayed enhancement [71, 80]. Specifically, when a patient presents with new LV dysfunction and echocardiographic wall motion abnormalities that are not in a typical coronary distribution, further focused testing should be employed to evaluate for myocarditis, myocardial infarction with nonobstructive coronary arteries (MINOCA), and other 
forms of cardiomyopathy [5]. Although not commonly used in clinical practice yet for the evaluation of myocardial fibrosis, cardiac CT has proven capable of detecting myocardial scar and assessing extracellular volume using late iodine contrast enhancement [81].

As previously noted, cardiac CT angiography (CTA) may be an acceptable alternative to TEE for the exclusion of left atrial appendage thrombus, when feasible [71, 73]. Similarly, multiphase cardiac CT has also been used for evaluation of endocarditis and paravalvular complications instead of TEE [71]. Coronary CTA has gained greater utility as a method to evaluate for coronary artery disease, for example, in the case of elevated troponin levels of unclear etiology, sometimes avoiding the need for invasive coronary angiography [71]. Limitations in elective stress testing due to the pandemic have also contributed to the increase in use of coronary CTA.

\section{Cardiac Magnetic Resonance Imaging}

Cardiac magnetic resonance imaging has rapidly emerged to become an important imaging modality used in the assessment of COVID-19-related myocardial injury. Due to its high resolution morphological and functional imaging capabilities, as well as tissue characterization, CMR is often used to aid in diagnosis of cardiomyopathies [82]. Some common barriers to widespread use of CMR use include metal incompatibilities, long scanning durations, gadolinium risks, patient claustrophobia, and high expense compared to other modalities (Table 1). More specific to the COVID-19 patient population, CMR can require a larger amount of disinfection time between scans, and patient variables such as stability, ventilation status, position, and ability to breath-hold can prevent acquisition of certain images [83]. However, society guidelines have provided practitioners with guidance on the safe CMR scanning of COVID-19 patients [84].

One of the primary advantages of CMR is the ability to help differentiate between ischemic and nonischemic myocardial injury. Although the gold standard for the diagnosis of myocarditis requires myocardial biopsy, the Lake Louise Consensus Criteria have provided proposed diagnostic criteria for myocarditis using standard CMR and later updated to include the use of parametric mapping techniques [82, 85]. Myocardial edema with late gadolinium enhancement (LGE) in a non-coronary distribution along with CMR tissue characterization (T1 and T2 mapping) showing increased T1 and T2, indicative of cardiac edema, inflammation, and fibrosis, may be seen in myocarditis. The largest study to date evaluating the utility of CMR in COVID-19 patients is a systematic review of 34 studies including 199 patients [86]. The study found that the most common diagnosis made by CMR in this population was myocarditis (40\%) with significant T1 and T2 mapping abnormalities, T2/short-T1 inversion recovery (STIR) edema, and LGE [86]. Other notable diagnoses that can be made with
CMR include pericarditis, MINOCA, and stress cardiomyopathy [87].

CMR has gained additional recognition and utility in patients clinically recovered from COVID-19. Puntmann et al. reported that $78 \%$ of recently recovered COVID-19 patients had an abnormality on CMR, and $60 \%$ had findings consistent with ongoing myocardial inflammation [88]. These findings raise concern for long-term $\mathrm{CV}$ complications secondary to COVID-19, even in asymptomatic patients. Similarly, studies of CMR performed after asymptomatic or mildly symptomatic COVID-19 infection in college-aged athletes found evidence of active myocardial inflammation in $15 \%$ and prior myocardial injury in $31 \%$ [89]. However, when compared to an athletic control group, $3 \%$ of recovered COVID-19-positive athletes had findings of myocarditis, with the only significant difference being increased midseptal edema in the COVID-19 group [90]. Further studies are needed to determine the optimal screening modality for long-term cardiac sequelae. Other forms of myocarditis showing LGE on CMR have correlated with malignant arrhythmias and sudden cardiac death in the convalescent phase of infection, and may serve as an important consideration in the management of COVID-19 survivors [91, 92]. CMR might additionally be a useful modality in making exercise recommendations post-COVID-19 in a select population, and publications discussing the issue of sports resumption after COVID-19 infection have emerged [93, 94].

\section{Nuclear Imaging Techniques}

Similar to other modalities, postponement of all non-urgent nuclear cardiology studies has been encouraged, and societal safety principles have been published [95, 96••]. When appropriate, pharmacologic rather than exercise stress testing has been encouraged to limit aerosol generation. Fluorodeoxyglucose (FDG) positron-emission tomography (PET) has been used as an alternative to TEE in the evaluation of suspected endocarditis during the pandemic [95]. In general, however, due to the inherent limitations in nuclear imaging studies, there has not been a specific clinical utility in this modality for COVID-19 patient evaluation [72]. FDGPET imaging is currently used clinically in diagnosis and risk assessment of other forms of myocarditis, most notably cardiac sarcoidosis [97]. This utility may add incremental value to the evaluation of COVID-19 myocarditis.

\section{Safety Precautions}

Regardless of the imaging modality used for patient care in the COVID-19 era, the safety of patients and healthcare providers remains a universal priority. The importance of proper PPE and limiting of testing to that which impacts patient health and 
Fig. 2 Flow chart illustrating the potential role of cardiovascular imaging in hospitalized patients with acute COVID-19 and suspected cardiac disease (a), and the role of imaging in the chronic care of recovered COVID-19 patients in the clinic setting (b)

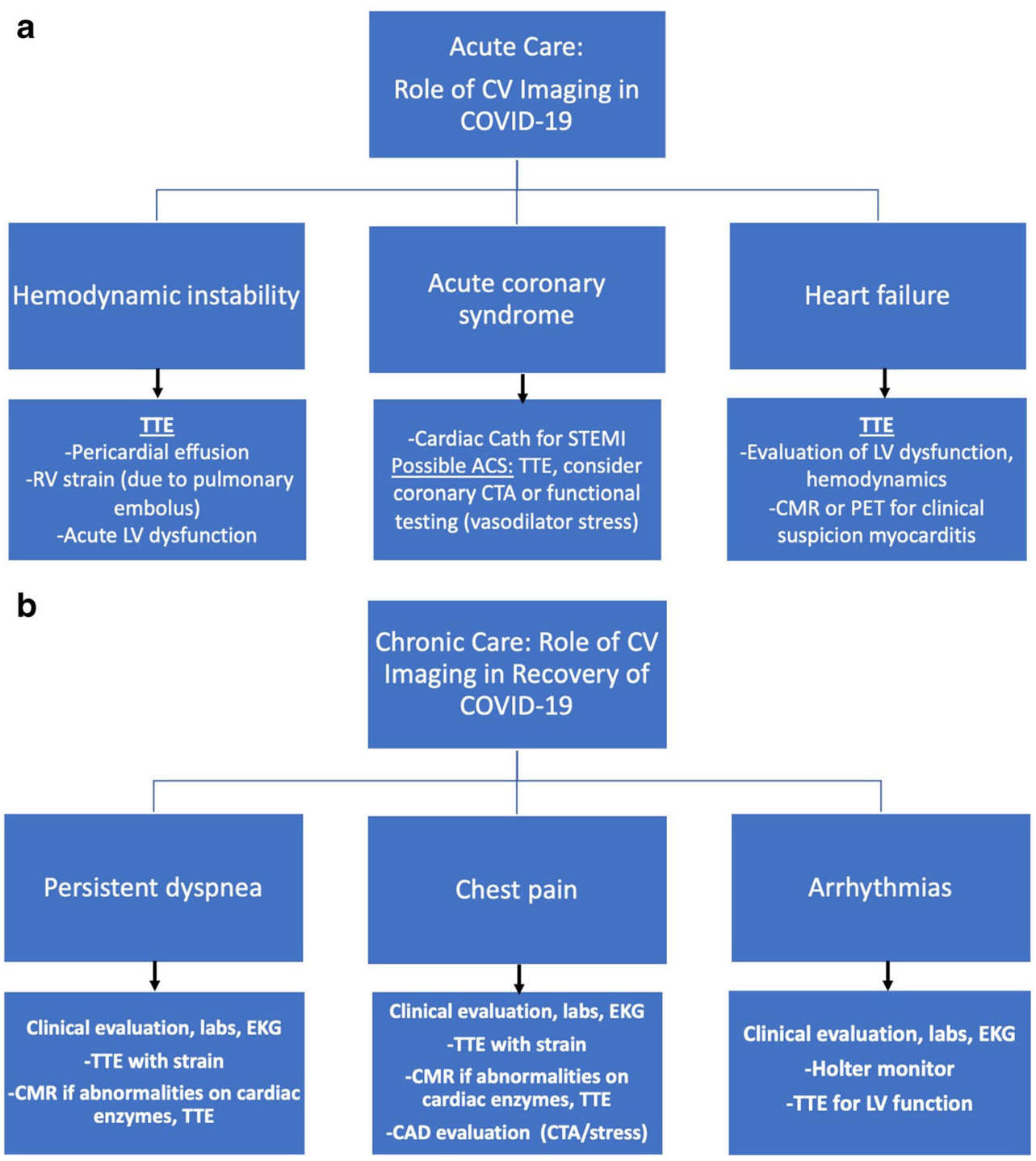

clinical management has been emphasized in COVID-19 recommendations [34, 84, 98]. Additional considerations include anticipating delays secondary to symptom screening, sanitizing practices, and case backlogs [96•*]. Choosing one best test for a patient can mitigate many infectious and logistical concerns. Therefore, it is beneficial for clinicians to know the strengths and limitations of available imaging modalities (Table 1).

\section{Conclusions}

As the pathophysiology and extent of possible CV involvement by COVID-19 is further recognized, the role of imaging in diagnosis, management, and prognosis of this disease will continue to evolve. Current society statements and guidelines recommend limiting imaging to that which is emergent or projected to change patient management [34,
36, 98, 99]. Tests that may answer clinical questions with less viral transmission risk are additionally preferable, when possible. In this light, echocardiography has become a primary tool for most COVID-19 patients with evidence of myocardial injury. CTA has become more heavily utilized for patients with suspected ischemic injury or thrombosis. For those with myocardial injury from nonischemic or unclear causes, CMR has taken on an important role. Early data suggests that CV consequences of COVID-19 can result in lasting subclinical myocardial inflammation or fibrosis detected on imaging. However, there are currently no standard guidelines on the optimal use of CV imaging in COVID-19 survivors with ongoing symptoms that may be cardiac, although the proposed clinical role of imaging in the acute and chronic setting (Fig. 2a and 2b) is reasonable considering the current evidence. It is likely that the role of $\mathrm{CV}$ imaging in post-COVID-19 care will continue to expand with ongoing investigation of this novel disease. 
Funding Dr Goerlich is supported by the Ruth L. Kirschstein Institutional National Research Service Award T32HL007227Pathophysiology of Myocardial Disease. Dr Minhas is supported by the National Heart, Lung, and Blood Institute training grant T32HL007024. Dr Mukherjee is supported by the Johns Hopkins Clinician Scientist Award, Johns Hopkins Magic That Matters Fund, NIH/NHLBI (R01 01HL114910), and the Department of Defense (W81XWH2010768). Dr Hays is supported by the Magic that Matters Fund of Johns Hopkins Medicine and National Institutes of Health/National Heart Lung and Blood Institute 1R01HL147660.

\section{Compliance with Ethical Standards}

Conflict of Interest The authors declare that they have no conflict of interest.

Human and Animal Rights and Informed Consent This article does not contain any studies with human or animal subjects performed by any of the authors.

\section{References}

Papers of particular interest, published recently, have been highlighted as:

- Of importance

•. Of major importance

1. Nandy S, Wan SH, Brenes-Salazar J. Cardiovascular manifestations of COVID-19. Curr Cardiol Rev. 2020;16. https://doi.org/ 10.2174/1573403X16999201102213827.

2. Nishiga M, Wang DW, Han Y, Lewis DB, Wu JC. COVID-19 and cardiovascular disease: from basic mechanisms to clinical perspectives. Nat Rev Cardiol. 2020;17(9):543-58. https://doi.org/10. 1038/s41569-020-0413-9.

3. Shi S, Qin M, Shen B, Cai Y, Liu T, Yang F, et al. Association of Cardiac injury with mortality in hospitalized patients with COVID19 in Wuhan, China. JAMA Cardiol. 2020;5(7):802-10. https://doi. org/10.1001/jamacardio.2020.0950.

4. Cordeanu EM, Duthil N, Severac F, Lambach H, Tousch J, Jambert $\mathrm{L}$, et al. Prognostic value of troponin elevation in COVID-19 hospitalized patients. J Clin Med. 2020;9(12). https://doi.org/10.3390/ jem9124078.

5. Rudski L, Januzzi JL, Rigolin VH, Bohula EA, Blankstein R, Patel $\mathrm{AR}$, et al. Multimodality imaging in evaluation of cardiovascular complications in patients with COVID-19: JACC Scientific Expert Panel. J Am Coll Cardiol. 2020;76(11):1345-57. https://doi.org/10. 1016/j.jacc.2020.06.080 This document was commissioned by the American College of Cardiology and provides a thorough guide for diagnosis of cardiac complications of COVID-19 along with clinical scenarios.

6. Citro R, Pontone G, Bellino M, Silverio A, Iuliano G, Baggiano A, et al. Role of multimodality imaging in evaluation of cardiovascular involvement in COVID-19. Trends Cardiovasc Med. 2021;31(1): 8-16. https://doi.org/10.1016/j.tcm.2020.10.001 This is the most current article on cardiac imaging in COVID-19 and provides a thorough review along with several helpful representative images.

7. Sandoval Y, Januzzi JL Jr, Jaffe AS. Cardiac troponin for assessment of myocardial injury in COVID-19: JACC review topic of the week. J Am Coll Cardiol. 2020;76(10):1244-58. https://doi.org/10. 1016/j.jacc.2020.06.068.
8. Metkus TS, Sokoll LJ, Barth AS, Czarny MJ, Hays AG, Lowenstein CJ, et al. Myocardial injury in severe COVID-19 compared to non-COVID acute respiratory distress syndrome. Circulation. 2020. https://doi.org/10.1161/CIRCULATIONAHA. 120.050543 This study importantly provides a non-COVID19 comparison group and found that myocardial injury in COVID-19 is moreso related to underlying comorbidities and severity of illness.

9. Lala A, Johnson KW, Januzzi JL, Russak AJ, Paranjpe I, Richter F, et al. Prevalence and impact of myocardial injury in patients hospitalized with COVID-19 infection. J Am Coll Cardiol. 2020;76(5): 533-46. https://doi.org/10.1016/j.jacc.2020.06.007.

10. Alvarez-Garcia J, Lee S, Gupta A, Cagliostro M, Joshi AA, RivasLasarte M, et al. Prognostic impact of prior heart failure in patients hospitalized with COVID-19. J Am Coll Cardiol. 2020;76(20): 2334 48. https://doi.org/10.1016/j.jacc.2020.09.549.

11. Chang WT, Toh HS, Liao CT, Yu WL. Cardiac involvement of COVID-19: a comprehensive review. Am J Med Sci. 2020;361:14 22. https://doi.org/10.1016/j.amjms.2020.10.002.

12. Krittanawong C, Kumar A, Hahn J, Wang Z, Zhang HJ, Sun T, et al. Cardiovascular risk and complications associated with COVID-19. Am J Cardiovasc Dis. 2020;10(4):479-89.

13. Fried JA, Ramasubbu K, Bhatt R, Topkara VK, Clerkin KJ, Horn E, et al. The variety of cardiovascular presentations of COVID-19. Circulation. 2020;141(23):1930-6. https://doi.org/10.1161/ CIRCULATIONAHA.120.047164.

14. Hendren NS, Drazner MH, Bozkurt B, Cooper LT Jr. Description and proposed management of the acute COVID-19 cardiovascular syndrome. Circulation. 2020;141(23):1903-14. https://doi.org/10. 1161/CIRCULATIONAHA.120.047349.

15. Cheng P, Zhu H, Witteles RM, Wu JC, Quertermous T, Wu SM, et al. Cardiovascular risks in patients with COVID-19: potential mechanisms and areas of uncertainty. Curr Cardiol Rep. 2020;22(5):34. https://doi.org/10.1007/s11886-020-01293-2.

16. Zhu H, Rhee JW, Cheng P, Waliany S, Chang A, Witteles RM, et al. Cardiovascular complications in patients with COVID-19: consequences of viral toxicities and host immune response. Curr Cardiol Rep. 2020;22(5):32. https://doi.org/10.1007/s11886-02001292-3.

17. Hoffmann M, Kleine-Weber H, Schroeder S, Kruger N, Herrler T, Erichsen S, et al. SARS-CoV-2 cell entry depends on ACE2 and TMPRSS2 and is blocked by a clinically proven protease inhibitor. Cell. 2020;181(2):271-80 e8. https://doi.org/10.1016/j.cell.2020. 02.052 .

18. Hamming I, Timens W, Bulthuis ML, Lely AT, Navis G, van Goor H. Tissue distribution of ACE2 protein, the functional receptor for SARS coronavirus. A first step in understanding SARS pathogenesis. J Pathol. 2004;203(2):631-7. https://doi.org/10.1002/path. 1570.

19. Liu PP, Blet A, Smyth D, Li H. The science underlying COVID-19: implications for the cardiovascular system. Circulation. $2020 ; 142$ (1):68-78. https://doi.org/10.1161/ CIRCULATIONAHA.120.047549.

20. Wichmann D. Autopsy findings and venous thromboembolism in patients with COVID-19. Ann Intern Med. 2020;173(12):1030. https://doi.org/10.7326/L20-1206.

21. Lindner D, Fitzek A, Brauninger $H$, Aleshcheva G, Edler C, Meissner K, et al. Association of cardiac infection with SARSCoV-2 in confirmed COVID-19 autopsy cases. JAMA Cardiol. 2020;5(11):1281-5. https://doi.org/10.1001/jamacardio.2020. 3551.

22. Varga Z, Flammer AJ, Steiger P, Haberecker M, Andermatt R, Zinkernagel AS, et al. Endothelial cell infection and endotheliitis in COVID-19. Lancet. 2020;395(10234):1417-8. https://doi.org/ 10.1016/S0140-6736(20)30937-5. 
23. Patel VB, Zhong JC, Grant MB, Oudit GY. Role of the ACE2/angiotensin 1-7 axis of the renin-angiotensin system in heart failure. Circ Res. 2016;118(8):1313-26. https://doi.org/10.1161/ CIRCRESAHA.116.307708.

24. Imai Y, Kuba K, Rao S, Huan Y, Guo F, Guan B, et al. Angiotensin-converting enzyme 2 protects from severe acute lung failure. Nature. 2005;436(7047):112-6. https://doi.org/10.1038/ nature03712.

25. Sattar Y, Ullah W, Rauf H, Virk HUH, Yadav S, Chowdhury M, et al. COVID-19 cardiovascular epidemiology, cellular pathogenesis, clinical manifestations and management. Int J Cardiol Heart Vasc. 2020;29:100589. https://doi.org/10.1016/j.ijcha.2020. 100589.

26. Zhang S, Liu Y, Wang X, Yang L, Li H, Wang Y, et al. SARSCoV-2 binds platelet ACE2 to enhance thrombosis in COVID-19. J Hematol Oncol. 2020;13(1):120. https://doi.org/10.1186/s13045020-00954-7.

27. Atri D, Siddiqi HK, Lang JP, Nauffal V, Morrow DA, Bohula EA. COVID-19 for the cardiologist: basic virology, epidemiology, cardiac manifestations, and potential therapeutic strategies. JACC Basic Transl Sci. 2020;5(5):518-36. https://doi.org/10.1016/j. jacbts.2020.04.002.

28. Mahmudpour M, Roozbeh J, Keshavarz M, Farrokhi S, Nabipour I. COVID-19 cytokine storm: the anger of inflammation. Cytokine. 2020;133:155151. https://doi.org/10.1016/j.cyto.2020.155151.

29. Lowenstein CJ, Solomon SD. Severe COVID-19 is a microvascular disease. Circulation. 2020;142(17):1609-11. https://doi.org/10. 1161/CIRCULATIONAHA.120.050354.

30. Qin C, Zhou L, Hu Z, Zhang S, Yang S, Tao Y, et al. Dysregulation of immune response in patients with coronavirus 2019 (COVID-19) in Wuhan, China. Clin Infect Dis. 2020;71(15):762-8. https://doi. org/10.1093/cid/ciaa248.

31. Fu Y, Cheng Y, Wu Y. Understanding SARS-CoV-2-mediated inflammatory responses: from mechanisms to potential therapeutic tools. Virol Sin. 2020;35(3):266-71. https://doi.org/10.1007/ s12250-020-00207-4.

32. Liu B, Li M, Zhou Z, Guan X, Xiang Y. Can we use interleukin-6 (IL-6) blockade for coronavirus disease 2019 (COVID-19)-induced cytokine release syndrome (CRS)? J Autoimmun. 2020;111: 102452. https://doi.org/10.1016/j.jaut.2020.102452.

33. Giustino G, Croft LB, Stefanini GG, Bragato R, Silbiger JJ, Vicenzi $\mathrm{M}$, et al. Characterization of myocardial injury in patients with COVID-19. J Am Coll Cardiol. 2020;76(18):2043-55. https://doi. org/10.1016/j.jacc.2020.08.069.

34.• Kirkpatrick JN, Mitchell C, Taub C, Kort S, Hung J, Swaminathan M. ASE statement on protection of patients and echocardiography service providers during the 2019 novel coronavirus outbreak: endorsed by the American College of Cardiology. J Am Coll Cardiol. 2020;75(24):3078-84. https://doi.org/10.1016/j.jacc.2020.04.002 This important document provides guidelines for clinicians on safe and appropriate utilization of all forms of echocardiography.

35. Hung J, Abraham TP, Cohen MS, Main ML, Mitchell C, Rigolin $\mathrm{VH}$, et al. ASE Statement on the reintroduction of echocardiographic services during the COVID-19 pandemic. J Am Soc Echocardiogr. 2020;33(8):1034-9. https://doi.org/10.1016/j.echo. 2020.05.019.

36. Ward RP, Lee L, Ward TJ, Lang RM. Utilization and appropriateness of transthoracic echocardiography in response to the COVID19 pandemic. J Am Soc Echocardiogr. 2020;33(6):690-1. https:// doi.org/10.1016/j.echo.2020.04.006.

37. Picard MH, Weiner RB. Echocardiography in the time of COVID19. J Am Soc Echocardiogr. 2020;33(6):674-5. https://doi.org/10. 1016/j.echo.2020.04.011.

38. Dweck MR, Bularga A, Hahn RT, Bing R, Lee KK, Chapman AR, et al. Global evaluation of echocardiography in patients with
COVID-19. Eur Heart J Cardiovasc Imaging. 2020;21(9):949-58. https://doi.org/10.1093/ehjci/jeaa178.

39. Wittstein IS, Thiemann DR, Lima JA, Baughman KL, Schulman SP, Gerstenblith G, et al. Neurohumoral features of myocardial stunning due to sudden emotional stress. N Engl J Med. 2005;352(6):539-48. https://doi.org/10.1056/NEJMoa043046.

40. Salah HM, Mehta JL. Takotsubo cardiomyopathy and COVID-19 infection. Eur Heart J Cardiovasc Imaging. 2020;21(11):1299-300. https://doi.org/10.1093/ehjci/jeaa236.

41. Minhas AS, Scheel P, Garibaldi B, Liu G, Horton M, Jennings M, et al. Takotsubo syndrome in the setting of COVID-19. JACC Case Rep. 2020;2(9):1321-5. https://doi.org/10.1016/j.jaccas.2020.04. 023.

42. Argulian E, Sud K, Bohra C, Vogel B, Garg V, Talebi S, et al. Safety of ultrasonic enhancing agents in patients with COVID-19. J Am Soc Echocardiogr. 2020;33(7):906-8. https://doi.org/10. 1016/j.echo.2020.04.022

43. Skulstad H, Cosyns B, Popescu BA, Galderisi M, Salvo GD, Donal E, et al. COVID-19 pandemic and cardiac imaging: EACVI recommendations on precautions, indications, prioritization, and protection for patients and healthcare personnel. Eur Heart J Cardiovasc Imaging. 2020;21(6):592-8. https://doi.org/10.1093/ehjci/jeaa072.

44. Szekely Y, Lichter Y, Taieb P, Banai A, Hochstadt A, Merdler I, et al. Spectrum of cardiac manifestations in COVID-19: a systematic echocardiographic study. Circulation. 2020;142(4):342-53. https://doi.org/10.1161/CIRCULATIONAHA.120.047971.

45. Bleeker GB, Steendijk P, Holman ER, Yu CM, Breithardt OA, Kaandorp TA, et al. Assessing right ventricular function: the role of echocardiography and complementary technologies. Heart. 2006;92 Suppl 1:i19-26. https://doi.org/10.1136/hrt.2005.082503.

46. Fayssoil A, Mustafic H, Mansencal N. The right ventricle in COVID-19 patients. Am J Cardiol. 2020;130:166-7. https://doi. org/10.1016/j.amjcard.2020.06.007.

47. van Dongen CM, Janssen MT, van der Horst RP, van Kraaij DJ, Peeters RH, van den Toorn LM, et al. Unusually rapid development of pulmonary hypertension and right ventricular failure after COVID-19 pneumonia. Eur J Case Rep Intern Med. 2020;7(7): 001784. https://doi.org/10.12890/2020_001784.

48. Creel-Bulos C, Hockstein M, Amin N, Melhem S, Truong A, Sharifpour M. Acute cor pulmonale in critically ill patients with Covid-19. N Engl J Med. 2020;382(21):e70. https://doi.org/10. 1056/NEJMc2010459.

49. Kim J, Volodarskiy A, Sultana R, Pollie MP, Yum B, Nambiar L, et al. Prognostic utility of right ventricular remodeling over conventional risk stratification in patients with COVID-19. J Am Coll Cardiol. 2020;76(17):1965-77. https://doi.org/10.1016/j.jacc. 2020.08.066.

50. Li Y, Li H, Zhu S, Xie Y, Wang B, He L, et al. Prognostic value of right ventricular longitudinal strain in patients with COVID-19. JACC Cardiovasc Imaging. 2020;13(11):2287-99. https://doi.org/ 10.1016/j.jcmg.2020.04.014.

51. Himebauch AS, Yehya N, Wang Y, McGowan FX, Mercer-Rosa L. New or persistent right ventricular systolic dysfunction is associated with worse outcomes in pediatric acute respiratory distress syndrome. Pediatr Crit Care Med. 2020;21(2):e121-e8. https://doi. org/10.1097/PCC.0000000000002206.

52. Nagueh SF, Smiseth OA, Appleton CP, Byrd BF 3rd, Dokainish H, Edvardsen T, et al. Recommendations for the evaluation of left ventricular diastolic function by echocardiography: an update from the American Society of Echocardiography and the European Association of Cardiovascular Imaging. J Am Soc Echocardiogr. 2016;29(4):277-314. https://doi.org/10.1016/j.echo.2016.01.011.

53. Goerlich E, Metkus TS, Gilotra NA, Wu KC, Cingolani OH, Hays AG. Prevalence and clinical correlates of echo-estimated right and left heart filling pressures in hospitalized patients with coronavirus 
disease 2019. Crit Care Explor. 2020;2(10):e0227. https://doi.org/ 10.1097/CCE.0000000000000227.

54. Demertzis ZD, Dagher C, Malette KM, Fadel RA, Bradley PB, Brar I, et al. Cardiac sequelae of novel coronavirus disease 2019 (COVID-19): a clinical case series. Eur Heart J Case Rep. 2020;4(FI1):1-6. https://doi.org/10.1093/ehjcr/ytaa179.

55. Dabbagh MF, Aurora L, D'Souza P, Weinmann AJ, Bhargava P, Basir MB. Cardiac tamponade secondary to COVID-19. JACC Case Rep. 2020;2(9):1326-30. https://doi.org/10.1016/j.jaccas. 2020.04.009.

56. Parsova KE, Pay L, Oflu Y, Haciyev R, Cinier G. A rare presentation of a patient with COVID-19: cardiac tamponade. Turk Kardiyol Dern Ars. 2020;48(7):703-6. https://doi.org/10.5543/ tkda.2020.56727.

57. Walker C, Peyko V, Farrell C, Awad-Spirtos J, Adamo M, Scrocco J. Pericardial effusion and cardiac tamponade requiring pericardial window in an otherwise healthy 30-year-old patient with COVID19: a case report. J Med Case Rep. 2020;14(1):158. https://doi.org/ 10.1186/s13256-020-02467-w.

58. Dalen H, Holte E, Guldal AU, Hegvik JA, Stensaeth KH, Braaten AT, et al. Acute perimyocarditis with cardiac tamponade in COVID-19 infection without respiratory disease. BMJ Case Rep. 2020;13(8). https://doi.org/10.1136/bcr-2020-236218.

59. Zhang L, Wang B, Zhou J, Kirkpatrick J, Xie M, Johri AM. Bedside focused cardiac ultrasound in COVID-19 from the Wuhan epicenter: the role of cardiac point-of-care ultrasound, limited transthoracic echocardiography, and critical care echocardiography. J Am Soc Echocardiogr. 2020;33(6):676-82. https://doi.org/ 10.1016/j.echo.2020.04.004.

60. Johri AM, Galen B, Kirkpatrick JN, Lanspa M, Mulvagh S, Thamman R. ASE Statement on point-of-care ultrasound during the 2019 novel coronavirus pandemic. J Am Soc Echocardiogr. 2020;33(6):670-3. https://doi.org/10.1016/j.echo.2020.04.017.

61. Kovell LC, Ali MT, Hays AG, Metkus TS, Madrazo JA, Corretti $\mathrm{MC}$, et al. Defining the role of point-of-care ultrasound in cardiovascular disease. Am J Cardiol. 2018;122(8):1443-50. https://doi. org/10.1016/j.amjcard.2018.06.054.

62. Convissar DL, Gibson LE, Berra L, Bittner EA, Chang MG. Application of lung ultrasound during the COVID-19 pandemic: a narrative review. Anesth Analg. 2020;131(2):345-50. https://doi. org/10.1213/ANE.0000000000004929.

63. Geyer H, Caracciolo G, Abe H, Wilansky S, Carerj S, Gentile F, et al. Assessment of myocardial mechanics using speckle tracking echocardiography: fundamentals and clinical applications. J Am Soc Echocardiogr. 2010;23(4):351-69; quiz 453-5. https://doi.org/ 10.1016/j.echo.2010.02.015.

64. Baycan OF, Barman HA, Atici A, Tatlisu A, Bolen F, Ergen P, et al. Evaluation of biventricular function in patients with COVID-19 using speckle tracking echocardiography. Int J Cardiovasc Imaging. 2020;37:135-44. https://doi.org/10.1007/s10554-02001968-5.

65. Janus SE, Hajjari J, Karnib M, Tashtish N, Al-Kindi SG, Hoit BD. Prognostic value of left ventricular global longitudinal strain in COVID-19. Am J Cardiol. 2020;131:134-6. https://doi.org/10. 1016/j.amjcard.2020.06.053.

66. Goerlich E, Gilotra NA, Minhas AS, Bavaro N, Hays AG, Cingolani OH. Prominent longitudinal strain reduction of basal left ventricular segments in patients with coronavirus disease-19. J Card Fail. 2020;27:100-4. https://doi.org/10.1016/j.cardfail.2020. 09.469.

67. Stobe S, Richter S, Seige M, Stehr S, Laufs U, Hagendorff A. Echocardiographic characteristics of patients with SARS-CoV-2 infection. Clin Res Cardiol. 2020;109(12):1549-66. https://doi. org/10.1007/s00392-020-01727-5.

68. Bleakley C, Singh S, Garfield B, Morosin M, Surkova E, Mandalia MS, et al. Right ventricular dysfunction in critically ill COVID-19
ARDS. Int J Cardiol. 2020;327:251-8. https://doi.org/10.1016/j. ijcard.2020.11.043.

69. Jaglan A, Roemer S, Jan MF, Khandheria BK. Myocardial work index: a glimmer of hope in COVID-19. Eur Heart J Cardiovasc Imaging. 2020;22:228. https://doi.org/10.1093/ehjci/jeaa181.

70. Minhas AS, Gilotra NA, Goerlich E, Garibaldi B, Metkus TS, Bavaro N, et al. Abstract 15455: Prevalence of subclinical myocardial dysfunction in hospitalized patients with Covid-19 and association with in-hospital mortality. Circulation. 2020;142. https://doi. org/10.1161/circ.142.suppl_3.15455.

71. Singh V, Choi AD, Leipsic J, Aghayev A, Earls JP, Blanke P, et al. Use of cardiac CT amidst the COVID-19 pandemic and beyond: North American perspective. J Cardiovasc Comput Tomogr. 2020;15:16-26. https://doi.org/10.1016/j.jcct.2020.11.004.

72. Cau R, Bassareo PP, Mannelli L, Suri JS, Saba L. Imaging in COVID-19-related myocardial injury. Int J Cardiovasc Imaging. 2020. https://doi.org/10.1007/s10554-020-02089-9.

73. Romero J, Husain SA, Kelesidis I, Sanz J, Medina HM, Garcia MJ. Detection of left atrial appendage thrombus by cardiac computed tomography in patients with atrial fibrillation. Circ Cardiovasc Imaging. 2013;6(2):185-94. https://doi.org/10.1161/ CIRCIMAGING.112.000153.

74. Secchi F, Di Leo G, Zanardo M, Ali M, Cannao PM, Sardanelli F. Detection of incidental cardiac findings in noncardiac chest computed tomography. Medicine (Baltimore). 2017;96(29):e7531. https://doi.org/10.1097/MD.0000000000007531.

75. Zhu ZW, Tang JJ, Chai XP, Fang ZF, Liu QM, Hu XQ, et al. Comparison of heart failure and COVID-19 in chest CT features and clinical characteristics. Zhonghua Xin Xue Guan Bing Za Zhi. 2020;48(6):467-71. https://doi.org/10.3760/cma.j.cn11214820200218-00093.

76. Bompard F, Monnier H, Saab I, Tordjman M, Abdoul H, Fournier L, et al. Pulmonary embolism in patients with COVID-19 pneumonia. Eur Respir J. 2020;56(1). https://doi.org/10.1183/13993003. 01365-2020.

77. Suh YJ, Hong H, Ohana M, Bompard F, Revel MP, Valle C, et al. Pulmonary embolism and deep vein thrombosis in COVID-19: a systematic review and meta-analysis. Radiology. 2020:203557. https://doi.org/10.1148/radiol.2020203557.

78. Sakr Y, Giovini M, Leone M, Pizzilli G, Kortgen A, Bauer M, et al. Pulmonary embolism in patients with coronavirus disease-2019 (COVID-19) pneumonia: a narrative review. Ann Intensive Care. 2020;10(1):124. https://doi.org/10.1186/s13613-020-00741-0.

79. Shamsah MA, Bitar ZI, Alfoudri H. Right atrial thrombus in a patient with COVID-19 pneumonia: a case report. Eur Heart J Case Rep. 2020;4(FI1):1-4. https://doi.org/10.1093/ehjcr/ytaa296.

80. Pontone G, Scafuri S, Mancini ME, Agalbato C, Guglielmo M, Baggiano A, et al. Role of computed tomography in COVID-19. J Cardiovasc Comput Tomogr. 2020;15:27-36. https://doi.org/10. 1016/j.jcct.2020.08.013.

81. Esposito A, Palmisano A, Barbera M, Vignale D, Benedetti G, Spoladore R, et al. Cardiac computed tomography in troponinpositive chest pain: sometimes the answer lies in the late iodine enhancement or extracellular volume fraction map. JACC Cardiovasc Imaging. 2019;12(4):745-8. https://doi.org/10.1016/j. jcmg.2018.08.013.

82. Ferreira VM, Schulz-Menger J, Holmvang G, Kramer CM, Carbone I, Sechtem U, et al. Cardiovascular magnetic resonance in nonischemic myocardial inflammation: expert recommendations. J Am Coll Cardiol. 2018;72(24):3158-76. https://doi.org/ 10.1016/j.jacc.2018.09.072.

83. Cau R, Bassareo P, Saba L. Cardiac involvement in COVID-19assessment with echocardiography and cardiac magnetic resonance imaging. SN Compr Clin Med. 2020;2:1-7. https://doi.org/10. 1007/s42399-020-00344-7. 
84. Allen BD, Wong TC, Bucciarelli-Ducci C, Bryant J, Chen T, Dall'Armellina E, et al. Society for Cardiovascular Magnetic Resonance (SCMR) guidance for re-activation of cardiovascular magnetic resonance practice after peak phase of the COVID-19 pandemic. J Cardiovasc Magn Reson. 2020;22(1):58. https://doi. org/10.1186/s12968-020-00654-8.

85. Friedrich MG, Sechtem U, Schulz-Menger J, Holmvang G, Alakija $\mathrm{P}$, Cooper LT, et al. Cardiovascular magnetic resonance in myocarditis: a JACC white paper. J Am Coll Cardiol. 2009;53(17):147587. https://doi.org/10.1016/j.jacc.2009.02.007.

86. Ojha V, Verma M, Pandey NN, Mani A, Malhi AS, Kumar S, et al. Cardiac magnetic resonance imaging in coronavirus disease 2019 (COVID-19): a systematic review of cardiac magnetic resonance imaging findings in 199 patients. J Thorac Imaging. 2020. https:// doi.org/10.1097/RTI.0000000000000574.

87. Cosyns B, Lochy S, Luchian ML, Gimelli A, Pontone G, Allard $\mathrm{SD}$, et al. The role of cardiovascular imaging for myocardial injury in hospitalized COVID-19 patients. Eur Heart J Cardiovasc Imaging. 2020;21(7):709-14. https://doi.org/10.1093/ehjci/ jeaa136.

88. Puntmann VO, Carerj ML, Wieters I, Fahim M, Arendt C, Hoffmann J, et al. Outcomes of cardiovascular magnetic resonance imaging in patients recently recovered from coronavirus disease 2019 (COVID-19). JAMA Cardiol. 2020;5(11):1265-73. https:// doi.org/10.1001/jamacardio.2020.3557.

89. Rajpal S, Tong MS, Borchers J, Zareba KM, Obarski TP, Simonetti $\mathrm{OP}$, et al. Cardiovascular magnetic resonance findings in competitive athletes recovering from COVID-19 infection. JAMA Cardiol. 2020. https://doi.org/10.1001/jamacardio.2020.4916.

90. Clark DE, Parikh A, Dendy JM, Diamond AB, George-Durrett K, Fish FA, et al. COVID-19 Myocardial Pathology Evaluation in AthleTEs with Cardiac Magnetic Resonance (COMPETE CMR). Circulation. 2020;143:609-12. https://doi.org/10.1161/ CIRCULATIONAHA.120.052573

91. Schumm J, Greulich S, Wagner A, Grun S, Ong P, Bentz K, et al. Cardiovascular magnetic resonance risk stratification in patients with clinically suspected myocarditis. J Cardiovasc Magn Reson. 2014;16:14. https://doi.org/10.1186/1532-429X-16-14.

92. Grani C, Eichhorn C, Biere L, Murthy VL, Agarwal V, Kaneko K, et al. Prognostic value of cardiac magnetic resonance tissue characterization in risk stratifying patients with suspected myocarditis. $\mathrm{J}$ Am Coll Cardiol. 2017;70(16):1964-76. https://doi.org/10.1016/j. jacc.2017.08.050.

93. Baggish A, Drezner JA, Kim J, Martinez M, Prutkin JM. Resurgence of sport in the wake of COVID-19: cardiac considerations in competitive athletes. Br J Sports Med. 2020;54(19):1130-1. https://doi.org/10.1136/bjsports-2020102516.

94. Phelan D, Kim JH, Elliott MD, Wasfy MM, Cremer P, Johri AM, et al. Screening of potential cardiac involvement in competitive athletes recovering from COVID-19: an expert consensus statement. JACC Cardiovasc Imaging. 2020;13(12):2635-52. https:// doi.org/10.1016/j.jcmg.2020.10.005.

95. Skali H, Murthy VL, Al-Mallah MH, Bateman TM, Beanlands R, Better N, et al. Guidance and best practices for nuclear cardiology laboratories during the COVID-19 pandemic: an information statement from ASNC and SNMMI. Circ Cardiovasc Imaging. 2020;13(9):e011761. https://doi.org/10.1161/CIRCIMAGING. 120.011761

96.• Zoghbi WA, MF DC, Blankstein R, Choi AD, Dilsizian V, Flachskampf FA, et al. Multimodality Cardiovascular imaging in the midst of the COVID-19 pandemic: ramping up safely to a new normal. JACC Cardiovasc Imaging. 2020;13(7):1615-26. https:// doi.org/10.1016/j.jcmg.2020.06.001 This document, developed by the editors of JACC Cardiovascular Imaging in collaboration with the Cardiovascular Imaging Counsel of the American College of Cardiology, provides guidance across all imaging modalities including choice of test, safety considerations, and scheduling considerations.

97. Hanneman K, Kadoch M, Guo HH, Jamali M, Quon A, Iagaru A, et al. Initial experience with simultaneous $18 \mathrm{~F}-\mathrm{FDG}$ PET/MRI in the evaluation of cardiac sarcoidosis and myocarditis. Clin Nucl Med. 2017;42(7):e328-e34. https://doi.org/10.1097/RLU. 0000000000001669 .

98. Choi AD, Abbara S, Branch KR, Feuchtner GM, Ghoshhajra B, Nieman K, et al. Society of cardiovascular computed tomography guidance for use of cardiac computed tomography amidst the COVID-19 pandemic endorsed by the American College of Cardiology. J Cardiovasc Comput Tomogr. 2020;14(2):101-4. https://doi.org/10.1016/j.jcct.2020.03.002.

99. Han Y, Chen T, Bryant J, Bucciarelli-Ducci C, Dyke C, Elliott MD, et al. Society for Cardiovascular Magnetic Resonance (SCMR) guidance for the practice of cardiovascular magnetic resonance during the COVID-19 pandemic. J Cardiovasc Magn Reson. 2020;22(1):26. https://doi.org/10.1186/s12968-020-00628-w.

Publisher's Note Springer Nature remains neutral with regard to jurisdictional claims in published maps and institutional affiliations. 